\title{
Plastic Changes in Lumbar Locomotor Networks after a Partial Spinal Cord Injury in Cats
}

\author{
Jean-Pierre Gossard, ${ }^{1}$ Hugo Delivet-Mongrain, ${ }^{1}{ }^{\circledR}$ Marina Martinez, ${ }^{2}$ Aritra Kundu, ${ }^{1}$ Manuel Escalona, ${ }^{1}$ \\ and Serge Rossignol ${ }^{1}$ \\ ${ }^{1}$ Groupe de Recherche sur le Système Nerveux Central, Department of Neurosciences, Université de Montréal, Montréal, Québec H3C3J7, Canada, and \\ ${ }^{2}$ Department of Cell Biology and Anatomy, Hotchkiss Brain Institute, University of Calgary, Calgary, Alberta T2N 4N1, Canada
}

\begin{abstract}
After an incomplete spinal cord injury (SCI), we know that plastic reorganization occurs in supraspinal structures with residual descending tracts. However, our knowledge about spinal plasticity is rather limited. Our recent studies point to changes within the spinal cord below the lesion. After a lateral left hemisection (T10), cats recovered stepping with both hindlimbs within 3 weeks. After a complete section (T13) in these cats, bilateral stepping was seen on the next day, a skill usually acquired after several weeks of treadmill training. This indicates that durable plastic changes occurred below the lesion. However, because sensory feedback entrains the stepping rhythm, it is difficult to reveal central pattern generator $(\mathrm{CPG})$ adaptation. Here, we investigated whether lumbar segments of cats with a chronic hemisection were able to generate fictive locomotion - that is, without phasic sensory feedback as monitored by five muscle nerves in each hindlimb. With a chronic left hemisection, the number of muscle nerves displaying locomotor bursts was larger on the left than on the right. In addition, transmission of cutaneous reflexes was relatively facilitated on the left. Later during the acute experiment, a complete spinalization (T13) was performed and clonidine was injected to induce rhythmic activities. There were still more muscle nerves displaying locomotor bursts on the left. The results demonstrate that spinal networks were indeed modified after a hemisection with a clear asymmetry between left and right in the capacity to generate locomotion. Plastic changes in $\mathrm{CPG}$ and reflex transmission below the lesion are thus involved in the stepping recovery after an incomplete SCI.
\end{abstract}

Key words: cat; CPG; electrophysiology; locomotion; reflex; spinal cord injury

\section{Introduction}

After a spinal cord injury (SCI), plastic reorganization can occur at different levels of the CNS above and below the lesion (Frigon and Rossignol, 2006; Roy et al., 2012). In contrast to reorganization within cortical or subcortical sensory and motor representation areas after SCI, our knowledge about plasticity below the lesion remains limited (Maier and Schwab, 2006; Zörner et al., 2014). A functional recovery can be seen after a lateral hemisection of the spinal cord and this model has been used in several studies to evaluate underlying changes due to disconnection from supraspinal tracts on the lesion side compared with the "intact" side (Murray and Goldberger, 1974; Little et al., 1988; Kunkel-Bagden et al., 1992; Helgren and Goldberger, 1993; Michele Basso, et al., 1994; Muir et al., 1998; Babu and Nama-

Received Oct. 30, 2014; revised April 2, 2015; accepted May 12, 2015.

Author contributions: J.-P.G., M.M., and S.R. designed research; J.-P.G., H.D.-M., M.M., A.K., and M.E. performed research; J.-P.G. analyzed data; J.-P.G. wrote the paper.

This work was supported by the Canadian Institutes of Health Research. A.K. and M.E. were supported by the Wings for Life Foundation. H.D.-M. and M.M. were supported by the Canadian Institutes of Health Research. All studies were conducted in the Department of Neurosciences at the Université de Montréal. We thank France Lebel for technical support with some of the experiments.

The authors declare no competing financial interests.

Correspondence should be addressed to Dr Jean-Pierre Gossard, Department of Neurosciences, Université de Montréal, C.P. 6128, Succursale Centre-ville, Montreal, Quebec H3C3J7, Canada. E-mail: jean-pierre.gossard@umontreal.ca.

DOI:10.1523/JNEUROSCI.4502-14.2015

Copyright $(\underset{2}{ } 2015$ the authors $\quad 0270-6474 / 15 / 359446-10 \$ 15.00 / 0$ sivayam, 2008; Doperalski et al., 2011). For example, after a hemisection (T12) in cats, sprouting of dorsal root terminals in spinal laminae paralleled the recovery of reflexes, locomotion, and hopping (Murray and Goldberger, 1974). If a partial SCI induces robust plasticity in neural circuitry below the lesion, then it should still be present even after a complete section. After a complete spinal transection during an acute experiment, cats with a chronic spinal cord hemisection displayed an enhanced reflex excitability on the side of the lesion leading to left/right asymmetries (Hultborn and Malmsten, 1983a; Hultborn and Malmsten, 1983b). In addition, Rossignol and colleagues investigated the plasticity of the locomotor system by comparing stepping before and after a left lateral hemisection (T10) and after a complete section (T13) 3 weeks later (Barrière et al., 2008; Martinez et al., 2011; Martinez et al., 2012). After the first lesion, cats could gradually recover quadrupedal locomotion over 3 weeks, but an asymmetry in stepping pattern persisted. Then, after the complete section, cats could step on the treadmill within hours of the complete lesion, with the left hindlimb walking before the right one. The reexpression of stepping after the T13 transection must reflect intrinsic changes below the lesion that occurred after the hemisection. In these spinal cats, walking was thus produced by adapted locomotor networks driven by sensory feedback. Adaptation of the central pattern generator (CPG) for locomotion has been proposed before to explain functional recovery after injury or training without direct electrophysiological evidence 
(De Leon et al., 1998; Raineteau and Schwab, 2001; Barrière et al., 2008; Ichiyama et al., 2008). Given the powerful action of sensory feedback on rhythm generators, it is difficult to reveal plasticity within the CPG based on walking patterns. Moreover, plasticity in reflex pathways is induced by treadmill training in spinal animals (Côté et al., 2003; Côté and Gossard, 2004; Lavrov et al., 2006; Frigon and Rossignol, 2008).

Here, we investigated whether there was a left-right asymmetry in the lumbar activity 3 weeks after a cord hemisection (T10) and after an additional acute complete transection (T13). We compared the CPG activity by looking at patterns of fictive locomotion on the left and right sides in decerebrate curarized animals; that is, without movements and sensory feedback. We also investigated whether there was a concomitant asymmetry in the gain of transmission in cutaneous pathways.

\section{Materials and Methods}

General procedure. In nine cats, the left half of the spinal cord was cut after a narrow laminectomy at T10 under sterile conditions. The wellbeing of the cats was monitored daily and verified regularly by a veterinarian. Cats were housed in large individual cages, with food and water and where they could stand freely. In the days after the lesions, foam mattresses were placed in the cages and cats were attended to a few times per day to express the bladder if necessary. Three weeks later, an acute terminal experiment was performed on these cats. In two "control" cats, the left hemisection at T10 was done during the acute experiment in the same way.

Acute experiments were performed on the 11 cats of either sex (2.3$4.6 \mathrm{~kg}$ ). All procedures were in accordance with the Guide for Care and Use of Experimental Animals (Canada) and approved by the Ethics Committee of the Universite de Montréal. The details of the preparation were described previously (Frigon and Gossard, 2010; Sirois et al., 2013) and are summarized here. Before surgery, cats were injected with an analgesic (Anafen $2 \mathrm{mg} / \mathrm{kg}$; subcutaneously) and premedicated (Atravet $0.001 \mathrm{mg} / \mathrm{kg}$, glycopyrrolate $0.01 \mathrm{mg} / \mathrm{kg}$, ketamine $5-10 \mathrm{mg} / \mathrm{kg}$, i.m.). Cats were anesthetized with a mask using a mixture of oxygen nitrous oxide and isoflurane (2-4\%, Abbott Laboratories). The level of anesthesia was adjusted throughout the surgery by monitoring blood pressure, applying pressure to the paw to detect limb withdrawal, and verifying the size and reactivity of the pupils.

After a craniotomy, the cortex and all tissue rostral to the colliculi and mammillary bodies were removed; that is, a precollicular/premammillary decerebration (Frigon and Gossard, 2010; Sirois et al., 2013). At this point, animals are considered to have complete lack of sentience. Anesthesia was discontinued and animals were paralyzed by injecting pancuronium bromide $(1 \mathrm{mg} / \mathrm{kg}$ ) (Sandoz Canada) through the right jugular or cephalic veins, supplemented every $45 \mathrm{~min}$. Paralysis is required to remove movement-related sensory feedback to study the centrally generated pattern of locomotion (i.e., "fictive" locomotion). Immediately after this injection, the animals were artificially ventilated for the duration of the experiment. In all cats, after a few hours of recording, a complete section at $\mathrm{T} 13$ was performed. A lethal injection of pentobarbital anesthetic was administered at the conclusion of the experiment through the right jugular vein. A piece of spinal cord (T9-T11) was dissected out and fixed in $10 \%$ paraformaldehyde for several weeks and then transferred to $30 \%$ sucrose solution for $72 \mathrm{~h}$. The tissue was frozen and $40-\mu \mathrm{m}$-thick coronal sections centered on the lesion were taken using a cryostat. Every section was mounted on a slide and stained with cresyl violet. Under microscope visualization, a qualitative evaluation of the damaged area was performed by using all the coronal sections in which the lesion was visible.

Nerve recording and stimulation. To monitor locomotor episodes, the electroneurography (ENG) of selected muscle nerves of both hindlimbs was recorded by dissecting and mounting the following cut nerves on bipolar silver chloride electrodes: posterior biceps-semitendinosus (PBSt), lateral gastrocnemius-soleus (LGS), medial gastrocnemius (MG), tibialis anterior (TA), extensor digitorum longus (EDL), and uncut sciatic nerve. The uncut cutaneous nerves superficial peroneal (SP) were also mounted on bipolar electrodes. After a laminectomy exposing spinal segments L6-S1, the animals were transferred to a stereotaxic frame and skin flaps surrounding the spinal cord and the hindlimb nerves were used to construct paraffin oil pools. The cord dorsum potential (CDP) was recorded with a silver-chloride ball electrode and stimulation intensity was expressed as multiples of the threshold ( $T$ ) for the most excitable fibers in the nerve determined by the first negative deflection of the CDP. In 4 cats with long episodes of fictive locomotion, SP nerves on both sides were stimulated $(2-3 \mathrm{~Hz})$ in alternation with single shocks of at intensity of $2.0 \mathrm{~T}$ to evoke reflexes. Electroneurograms were bandpass filtered $(10 \mathrm{~Hz}-10 \mathrm{kHz})$ and amplified (Neuralynx).

In cats with intact spinal cord, episodes of fictive locomotion were occurring spontaneously after decerebration. After a chronic lateral hemisection, a short series of electrical stimuli ( 50 pulses, $200 \mathrm{~Hz}, 5.0 \mathrm{~T})$ to the sciatic nerves on both sides were used to trigger (never to maintain) episodes. After the complete section at T13, clonidine was injected (200$500 \mu \mathrm{g} / \mathrm{kg}$, i.v.) and episodes were initiated by manually stimulating the perineum. Episodes of fictive stepping were digitized online (5000 A/D rate) with an interactive custom-made software (Spinal Cord Research Center, University of Manitoba, Winnipeg, Canada) or offline from recordings on videotape (15 channels; 4000A, A.R. Vetter). Data were analyzed using the same custom-made software.

Burst duration was defined as the time between burst onset and termination and was determined from the rectified waveforms using an adaptive threshold crossing method (Frigon and Gossard, 2009). Cycle period was defined as the time between successive flexor or extensor burst onsets. Regression lines were fitted to scatter plots of burst duration relative to its corresponding cycle period. Coefficients of linear regression were calculated using statistical software (SPSS version 15.0). For extensor or flexor burst selection, the ENG with the best signal-to-noise ratio was used. The ENGs from LGS or MG were used as extensor bursts, whereas the ENG from TA was used for flexor bursts. In many cases, there was an absence of bursts of activity in nerves of antagonist muscles on the right side after a chronic hemisection. In these instances, for comparison purposes, we measured the duration of the silent periods between two bursts (estimated antagonist phase) to determine whether this interval varied with the cycle duration (Frigon and Gossard, 2010).

Reflexes in the TA nerves evoked by stimulating the left and right SP nerves were measured from the rectified TA ENG. Only the peak amplitude of the first excitatory response was measured using predefined latencies as guidelines (Duysens and Pearson, 1976; Duysens and Loeb, 1980; Abraham et al., 1985). The latency between the incoming cutaneous volley recorded as the CDP and the onset of the excitatory response varied by a few milliseconds depending on the length of the nerve, so the window to measure the early excitatory reflex amplitude was adjusted for each nerve. The amplitude from an equivalent area in ENG occurring just before the reflex was subtracted. The amplitude just before the reflex also represents the amplitude of the underlying locomotor burst (or absence of) at the time of the stimulus. Plots of reflex amplitude against the underlying burst amplitude were constructed to evaluate the input-output gain in cutaneous reflex transmission (Capaday and Stein, 1986; Bennett et al., 1996; Simonsen and Dyhre-Poulsen, 1999). Regression lines were fitted to scatter plots of reflex amplitude relative to burst ENG amplitude and coefficients were calculated using the same software.

Statistical analysis. All statistical tests were done using SPSS version 15.0. A simple linear regression was performed between burst duration (that is, dependent variable) and cycle period (i.e., independent variable) and an $F$ test was used to determine whether the regression was significant. An ANCOVA test was performed to reveal significant difference in the slopes of the regression lines. This analysis was performed because cycle period can co-vary (or remain invariant) with the extensor or flexor phase concomitantly. A locomotor episode was extensor or flexor dominated if there was a significant linear relationship or a significant difference between the slopes of the extensor and flexor regression lines. If the slope of the linear regression was steeper for extension than flexion, the cycle duration was said to be extensor dominated; if the slope of the linear regression was steeper for flexion than extension, the cycle duration was said to be flexor dominated (Fleshman et al., 1984; Yakovenko et al., 2005). Where relevant, the coefficients of determination $R 2$ ) are given in 
A Intact cord
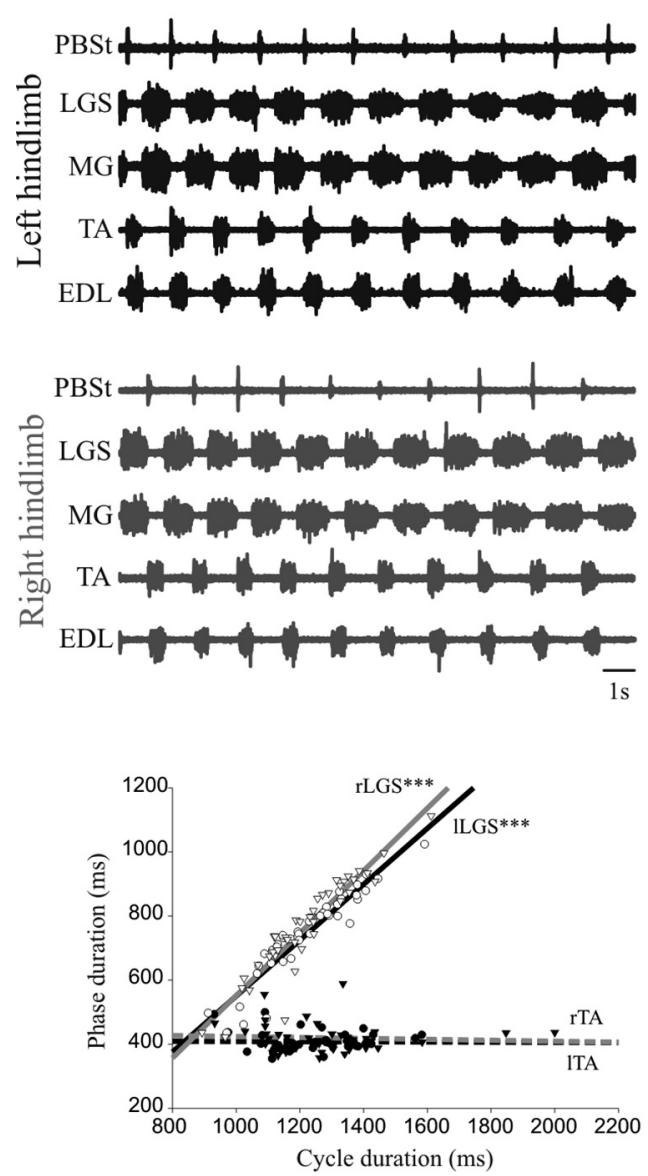

B

Acute left hemisection at $\mathrm{T} 10$
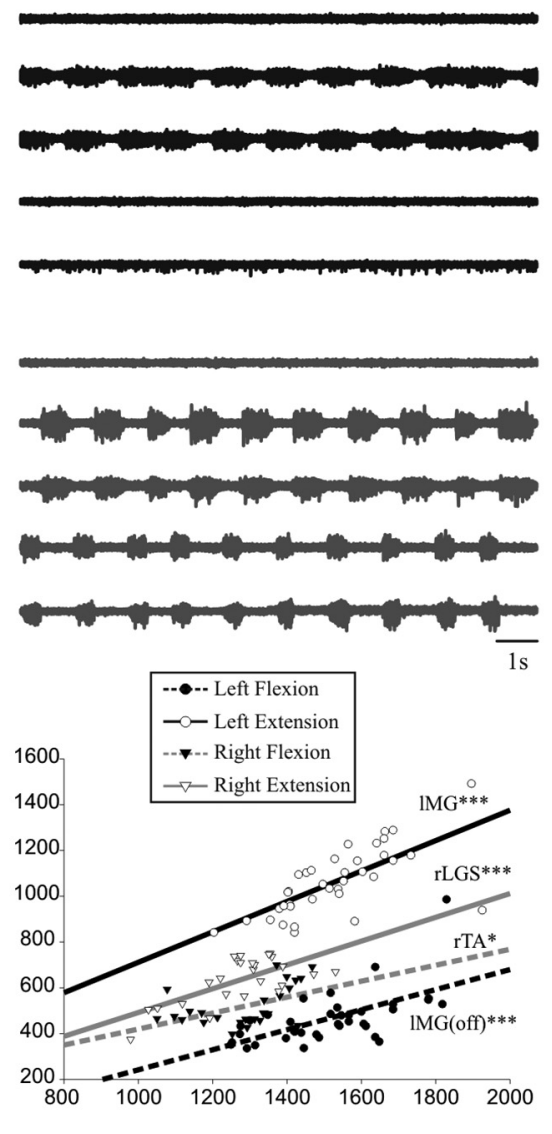

C

Chronic left hemisection at $\mathrm{T} 10$
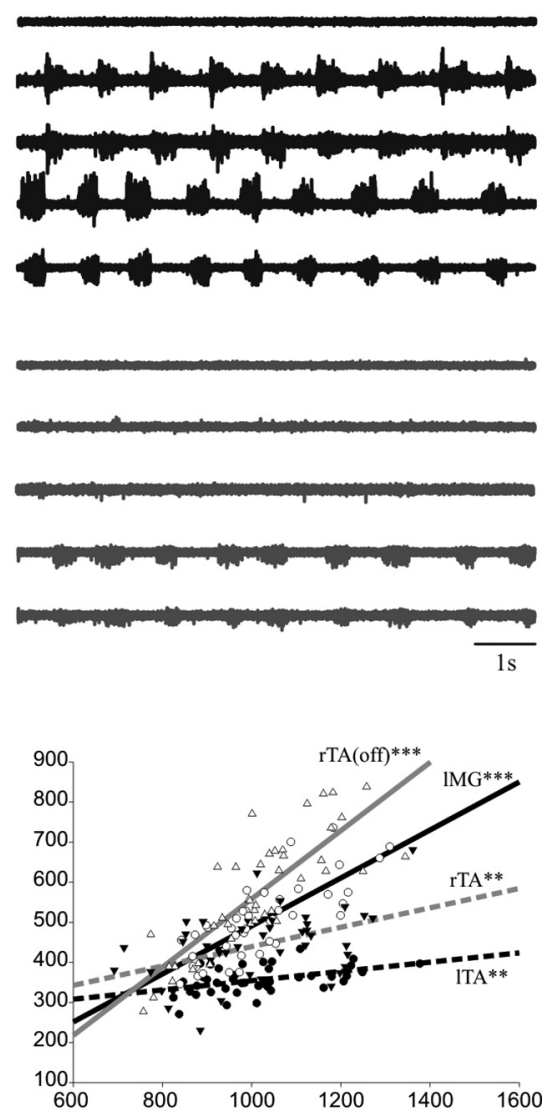

Figure 1. Electroneurographic activity in left hindlimb (black) and in right hindlimb (gray). $\boldsymbol{A}$, Bilateral fictive locomotion in a cat with an intact spinal cord. The bursts of activity in extensor nerves in the left hindlimb alternated with bursts in flexor nerves and with bursts form the contralateral extensor nerves. $\boldsymbol{B}$, In the same cat after an acute left hemisection, bursts of activity occurred in two nerves (both extensors) in the left hindlimb and in four nerves in the right hindlimb. C, In a cat with a chronic left hemisection ( 3 weeks), there were bursts of activity in 4 nerves in the left hindlimb and weaker bursts of activity in 2 nerves (both flexors) in the right hindlimb. Under each episode of fictive locomotion is a plot showing the linear relationship between the cycle duration and the phase duration. As shown in the inset, the phases on the left lesioned side are represented by empty circles (extension, LGS, or MG) and filled circles (flexion, TA); the phases on the right side, by empty triangles (extension, LGS or MG) and filled triangles (flexion, TA). For left and right, the linear regression for extension is represented as solid lines and for flexion as dashed lines. The intervals between two MG bursts [silent periods, "IMG(off)"] on the left can approximate the duration of flexor bursts. IMG is left MG; ITA, left TA; rTA, right TA. ${ }^{*} p<0.05$; ${ }^{* *} p<0.01$; ${ }^{* * *} p<0.001$.

the text. An ANCOVA analysis was also performed for comparing the linear regressions relating cutaneous reflexes and burst amplitude on both sides. A simple $t$ test was applied to compare the number of active nerves on both sides in hemisected cats and after the acute spinalization at T13. Significance was set at $p<0.05$.

\section{Results}

Patterns of fictive locomotion in the left and right side

Figure $1 A$ shows the fictive locomotor pattern from nerves recorded in both hindlimbs of a cat with an intact spinal cord. Episodes such as this occurred spontaneously after decerebration. The flexors and extensors were clearly alternating in each limb and agonists were alternating on each side. The analysis of duration of phases of activity and cycle indicates that the cycle duration was linearly related to the extension phase (LGS bursts) on the left $\left(R^{2}=0.878\right)$ and on the right $\left(R^{2}=0.871\right)$, but not to the duration of flexion phase (TA bursts). The locomotor cycle on both sides was clearly extensor dominated, as in intact walking cats (Frigon and Gossard, 2009; Gossard et al., 2011; Zhong et al., 2012).

Figure $1 B$ shows the locomotor pattern occurring 3 min after an acute hemisection on the left side at T10 in that same animal.
This episode was triggered by short trains to the sciatic nerves (See Materials and Methods). There are rhythmic bursts of small amplitude in the two ankle extensor nerves on the left side with variable duration. On the right side, however, apart from the absence of bursts in the knee flexor PBSt, there are clear alternating bursts in flexors and extensors as before the lesion. There was thus an obvious asymmetry in the activity of locomotor networks between left and right, with the side of the lesion (left) being much weaker. This is rather expectable considering that all supraspinal tracts had been suddenly severed on the left, including the descending drive from the brainstem. Analysis of the duration of phases and cycle showed that the cycle duration on the left side was linearly related to the extension phase $\left(R^{2}=0.478\right)$. Because there were no flexor bursts, it is impossible to do the same analysis for the flexion phase. However, an alternative is to use the silent periods between extensor bursts as a rough estimate of the duration of the flexion phase even though such durations may not be exactly the same (Frigon and Gossard, 2010). This analysis showed that the cycle duration was linearly related to the silent periods between extensor bursts $\left(R^{2}=0.366\right)$. Moreover, there was no statistical difference between the two slopes, so the cycle 
A Acute spinalization (+ clonidine)

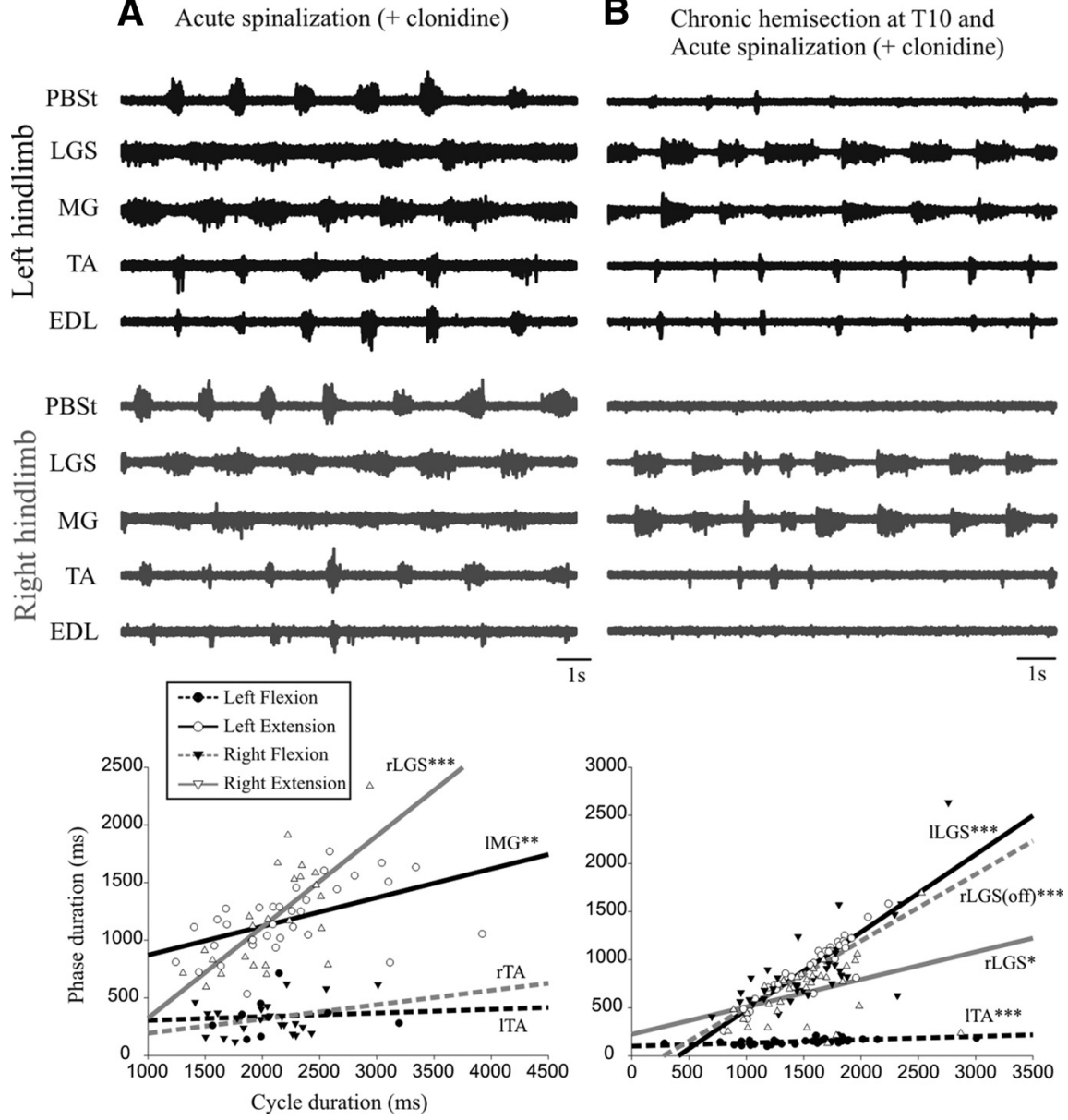

Figure 2. Electroneurographic activity in left (in black) and right (in gray) hindlimb after a complete spinalization at T13. $\boldsymbol{A}_{\text {, }}$ Bilateral fictive locomotion occurred after an acute spinalization in a cat with no chronic hemisection (same cat as in Fig. $1 A, B$ ). There were bursts of activity in all nerves in the left and right hindlimbs. $\boldsymbol{B}$, Fictive locomotion occurred after an acute spinalization with injection of clonidine in a cat with a previous chronic hemisection at T10 (same cat as in Fig. 1C). Bursts of activity were generated in four nerves with a weak activity in PBSt in the left hindlimb. The right hindlimb displayed rhythmic bursts in two nerves (both extensors) with rare bursts in the flexor nerve (TA). Under each episode of fictive locomotion is a plot showing the linear relationship between the cycle duration and the phase duration with the same outline as Figure 1.

duration covaried with the extension and with the "pseudo-flexion" phases. On the right side, the cycle duration also covaried with extension $\left(R^{2}=0.461\right)$ and flexion $\left(R^{2}=0.243\right)$ phases and there was no statistical difference between these slopes. The cycle duration, which was extensor dominated on both sides with an intact cord, varies with the duration of both phases after an acute hemisection.

Figure $1 C$ shows the pattern of fictive locomotion in a cat with a chronic left hemisection at T10 performed 3 weeks before the acute experiment. This rhythm appeared spontaneously after decerebration. The nerves on the left hindlimb display regular alternating bursts in flexors and extensors, whereas only the nerves of ankle (TA) and toe (EDL) flexors are rhythmically active on the right side. There was thus a clear asymmetry in the activity between left and right locomotor networks, with a weak locomotor pattern on the right side that was connected to the brain. This asymmetry is strikingly opposed to what was observed with an acute hemisection (Fig. 1B). The cycle duration on the left side covaried with the duration of both extension $\left(R^{2}=0.605\right)$ and flexion $\left(R^{2}=0.202\right)$ phase, but the slope for extension was statistically steeper than for flexion; that is, extensor dominated. The cycle duration of the right was linearly related to the flexion $\left(R^{2}\right.$ $=0.205)$ phase and also to the duration of the silent periods (pseudo-extension, $R^{2}=0.667$ ) and this last slope was steeper than for flexion (i.e., extensor dominated).

Such asymmetry could be due to locomotor networks being skewed by asymmetric descending drive over the 3 week period and/or to plastic changes that are intrinsic to the spinal circuitry below the lesion. In an attempt to disclose some of the spinal plasticity, we also studied the locomotor patterns in these cats after an additional acute complete spinalization at $\mathrm{T} 13$. This segment was chosen because it is the most common spinal level used in previous work with spinal cats. Not surprisingly, there was a decrease in the overall excitability of the isolated lumbar segments (Smith and Jeffery, 2005) and clonidine injection and perineal stimulation were therefore necessary to induce rhythmic activity in all cats. Figure $2 A$ shows the pattern of fictive locomotion after a complete spinal section at $\mathrm{T} 13$ in a control cat (same cat as in Fig. 1A,B). There are clear rhythmic activities in all nerves on both sides with alternating flexor and extensor bursts, as well as alternating agonists between left and right. The cycle duration was linearly related to the extension phase on the left $\left(R^{2}=0.257\right)$ and right $\left(R^{2}=0.500\right)$ side, but not to the flexion phase; the cycle duration on each side was thus extensor dominated.

Figure $2 B$ shows the locomotor pattern in a cat with a chronic left hemisection (the same as in Fig. 1C), after the acute spinalization (and intravenous clonidine). Rhythmic bursts are seen in all nerves on the left hemisected side and mostly in ankle extensors on the right side. The cycle duration on the left side was linearly related to the duration of both extension $\left(R^{2}=0.875\right)$ and flexion $\left(R^{2}=0.35\right)$ phases, but the slope for extension was statistically steeper than for flexion; that is, extensor dominated (as in Fig. 1C). The cycle duration on the right side was linearly related to extension $\left(R^{2}=\right.$ 0.153 ) and the silent period between extensor bursts (sham flexion; $R^{2}=0.551$ ), but the slope for the sham flexion was statistically steeper than for extension; that is, the cycle was flexor dominated.

Figure 3 shows the fictive locomotion in another cat with a chronic left hemisection at T10 after decerebration and after an acute complete section at T13. After decerebration, there were five nerves in the left hindlimb with clear bursts of activity alternating between flexors and extensors, whereas in the right hindlimb, there were weak bursts of activity in flexors (Fig. $3 A$ ). The cycle duration on the left side covaried with the duration of extension $\left(R^{2}=0.285\right)$ and flexion $\left(R^{2}=0.448\right)$ phases. The cycle duration of the right side also covaried with the flexion phase $\left(R^{2}=0.205\right)$ and the silent periods between flexor bursts (pseudo-extension, $R^{2}=0.410$ ).

It is important to realize that weaknesses in - or absence of locomotor bursts on the right were not due to depressed excit- 
A

Chronic left hemisection at $\mathrm{T} 10$
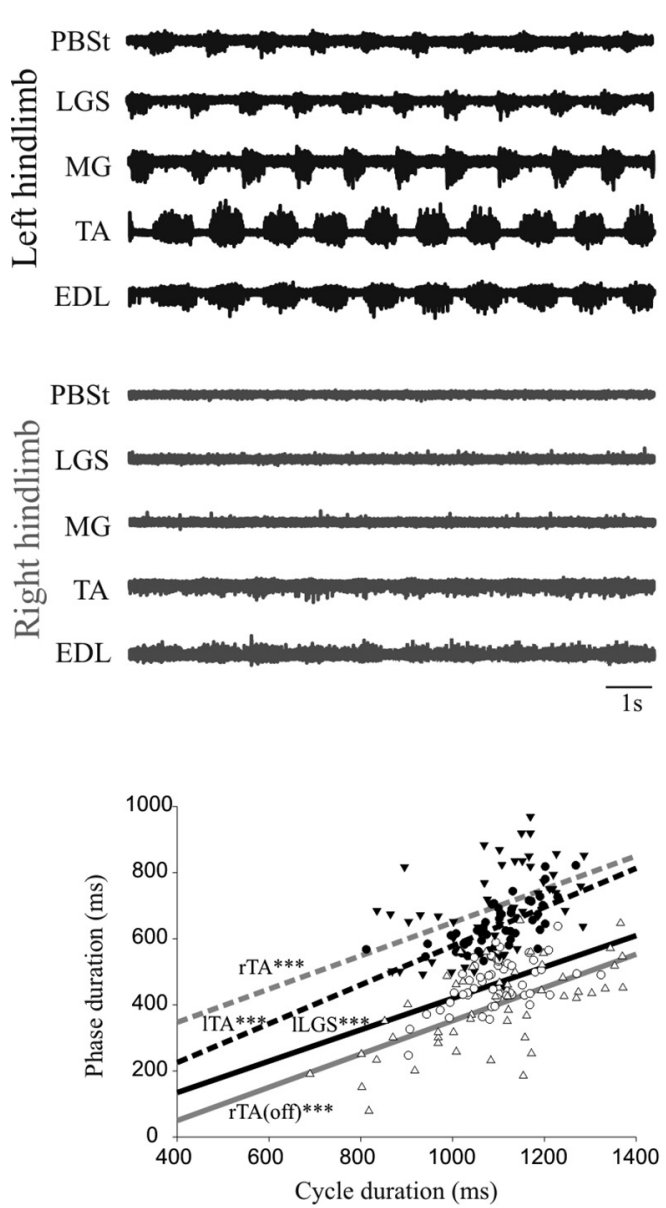

B

Responses to sciatic nerve stimulation

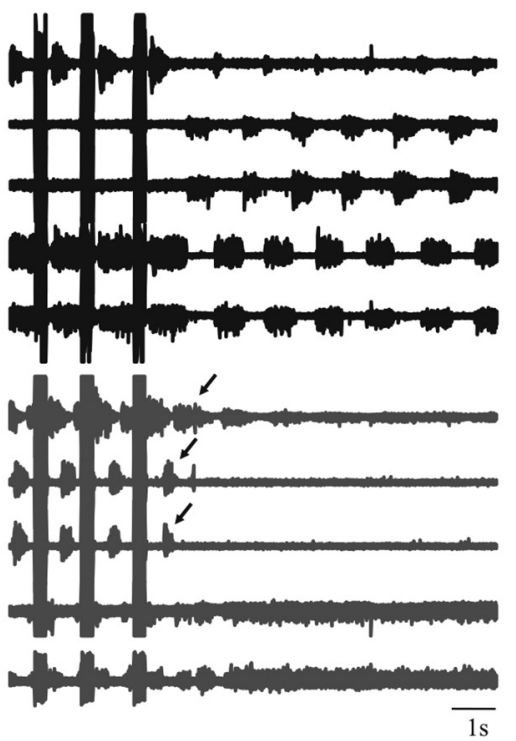

C Chronic left hemisection at T10 and Acute spinalization (+ clonidine)

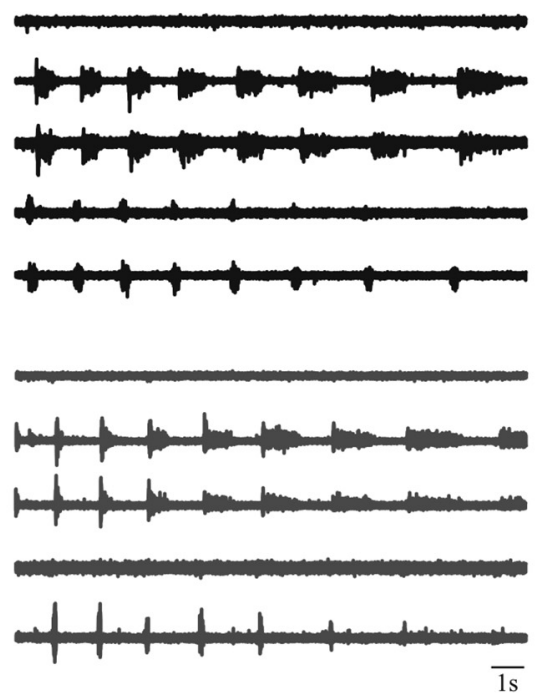

Figure 3. Electroneurographic activity in the left (black) and in the right (gray) hindlimb in a cat with a chronic left hemisection ( 3 weeks). $A$, There were bursts of activity in all five nerves in the left hindlimb and weaker bursts of activity in two nerves (both flexors) in the right hindlimb. $\boldsymbol{B}$, During a period of inactivity, trains of stimuli in the sciatic nerve $(50 \mathrm{pulses}, 200 \mathrm{~Hz}, 5.0 \mathrm{~T}$ ) were given to trigger an episode of rhythmic activities. After the stimuli, clear bursts of activity (arrows) were generated in PBSt and two extensor nerves (MG and LGS) on the right side, yet these nerves were silent during the ensuing episode of fictive locomotion (as in $A$ ). $C$, In the same cat, fictive locomotion occurred after an acute spinalization with injection of clonidine. There were rhythmic bursts in four nerves in the left hindlimb and in three nerves in the right hindlimb (two extensors and one flexor). Under the episode of fictive locomotion in $\boldsymbol{A}$ and $\boldsymbol{C}$ is a plot showing the linear relationship between the cycle duration and the phase duration with the same outline as Figure 1.

ability of motor pools because bursts could be clearly evoked via reflex pathways. For example, Figure $3 B$ shows the triggering of an episode of fictive locomotion on the left after 3 trains of stimuli ( 50 imps, $200 \mathrm{~Hz}, 5 \mathrm{~T}$ ) in the sciatic nerve on the right side. Note that clear bursts are evoked (arrows) in the knee flexor (PBSt) and ankle extensors (LGS, MG) on the right. However, the same nerves were silent during the ensuing episode of rhythmic activities on the left. After a complete spinalization at T13 and clonidine injection in the same cat, there were four nerves with locomotor bursts in the left hindlimb and three nerves in the right hindlimb (Fig. 3C), including the ankle extensors that were silent before the spinalization. The cycle duration on the left side was linearly related to the duration the extension phase $\left(R^{2}=0.975\right)$, but not the flexion phase, so it was extensor dominated. The cycle duration of the right was linearly related to the duration of both the extension phase $\left(R^{2}=0.911\right)$ and the silent periods (sham flexion, $R^{2}=0.880$ ), but the slope for extension was significantly steeper than for flexion; that is, extensor-dominated.

Overall, after a left chronic hemisection at T10 (3 weeks) in 9 cats, there were 36 nerves with bursts of activity on the left side and 15 active nerves on the right side (Table 1 ) which is significantly different $(p<0.001)$. We measured the phase to cycle relationships in six cats with the longest episodes of locomotion. The cycle was extensor dominated in four of six cats on the left side and there was no difference in slopes in two of six cats. On the right side, there was no difference in slopes in four of six cats and, in two of six cats, the cycle was extensor dominated. The results indicate that the activity of locomotor networks was stronger on the left, hemisected side than on right side.

After a complete section at T13 in seven chronic hemisected cats, there were overall 33 nerves with bursts of activity on the left side and 25 on the right side (Table 1 ), which is statistically different $(p=0.026)$. The cycle was extensor dominated in five of six cats on the left side (one covaried). On the right side, the cycle was extensor dominated in two of six cats, flexor dominated in two, and covaried in two. Therefore, even when all remaining supraspinal tracts are disconnected from the right side, the locomotor rhythm on the left side was more robust. Even though spinal circuitry of both sides received the same pharmacological 
Table 1. Histology and number of active nerves

\begin{tabular}{|c|c|c|c|c|c|c|c|c|c|c|c|}
\hline Exp & 1 & 2 & 3 & 4 & 5 & 6 & 7 & 8 & 9 & Control1 & Control2 \\
\hline $\begin{array}{c}\text { Days post- } \\
\text { lesion }\end{array}$ & 21 & 22 & 20 & 22 & 21 & 23 & 21 & 22 & 23 & 0 & 0 \\
\hline left leg & $\begin{array}{c}3 \\
\text { (PBSt, TA, EDL) }\end{array}$ & $\begin{array}{c}3 \\
\text { (PBSt, TA, EDL) }\end{array}$ & $\begin{array}{c}3 \\
\text { (PBSt, TA, EDL) }\end{array}$ & $\begin{array}{c}5 \\
\text { (PBSt, TA, EDL, } \\
\text { LGS, MG) }\end{array}$ & $\begin{array}{c}4 \\
\text { (TA, EDL, LGS, } \\
\text { MG) }\end{array}$ & $\begin{array}{c}4 \\
\text { (TA, EDL, LGS, } \\
\text { MG) }\end{array}$ & $\begin{array}{c}5 \\
\text { (PBSt, TA, EDL, } \\
\text { LGS, MG) }\end{array}$ & $\begin{array}{c}5 \\
\text { (PBSt, TA, EDL, } \\
\text { LGS, MG) }\end{array}$ & $\begin{array}{c}4 \\
\text { (TA, EDL, LGS, } \\
\text { MG) }\end{array}$ & $\begin{array}{c}5 \\
\text { (PBSt, TA, EDL, } \\
\text { LGS, MG) }\end{array}$ & $\begin{array}{c}5 \\
\text { (PBSt, TA, EDL, } \\
\text { LGS, MG) }\end{array}$ \\
\hline right leg & $\begin{array}{c}2 \\
\text { (TA, EDL) }\end{array}$ & 0 & 0 & $\begin{array}{c}3 \\
\text { (PBSt, TA, EDL) }\end{array}$ & $\begin{array}{c}3 \\
\text { (EDL, LGS, MG) }\end{array}$ & $\begin{array}{c}3 \\
\text { (TA, EDL, LGS) }\end{array}$ & $\begin{array}{c}2 \\
\text { (TA, EDL) }\end{array}$ & $\begin{array}{l}1 \\
\text { (LGS) }\end{array}$ & $\begin{array}{l}1 \\
\text { (LGS) }\end{array}$ & $\begin{array}{c}5 \\
\text { (PBSt, TA, EDL, } \\
\text { LGS, MG) }\end{array}$ & $\begin{array}{c}5 \\
\text { (PBSt, TA, EDL, } \\
\text { LGS, MG) }\end{array}$ \\
\hline $\begin{array}{c}\text { Spinal T13 } \\
\text { left leg }\end{array}$ & & & $\begin{array}{c}4 \\
\text { (PBSt, TA, EDL, } \\
\text { LGS) }\end{array}$ & $\begin{array}{c}5 \\
\text { (PBSt, TA, EDL, } \\
\text { LGS, MG) }\end{array}$ & $\begin{array}{c}4 \\
\text { (TA, EDL, LGS, } \\
\text { MG) }\end{array}$ & $\begin{array}{c}5 \\
\text { (PBSt, TA, EDL, } \\
\text { LGS, MG) }\end{array}$ & $\begin{array}{c}5 \\
\text { (PBSt, TA, EDL, } \\
\text { LGS, MG) }\end{array}$ & $\begin{array}{c}5 \\
\text { (PBSt, TA, EDL, } \\
\text { LGS, MG) }\end{array}$ & $\begin{array}{c}5 \\
\text { (PBSt, TA, EDL, } \\
\text { LGS, MG) }\end{array}$ & & $\begin{array}{c}4 \\
\text { (TA, EDL, LGS, } \\
\text { MG) }\end{array}$ \\
\hline $\begin{array}{l}\text { Spinal T13 } \\
\text { right leg }\end{array}$ & & & $\begin{array}{c}2 \\
\text { (PBSt, LGS) }\end{array}$ & $\begin{array}{c}5 \\
\text { (PBSt, TA, EDL, } \\
\text { LGS, MG) }\end{array}$ & $\begin{array}{c}4 \\
\text { (PBSt, EDL, LGS, } \\
\text { MG) }\end{array}$ & $\begin{array}{c}3 \\
\text { (PBSt, LGS, } \\
\text { MG) }\end{array}$ & $\begin{array}{c}4 \\
\text { (PBSt, EDL, LGS, } \\
\text { MG) }\end{array}$ & $\begin{array}{c}4 \\
\text { (TA, EDL, LGS, } \\
\text { MG) }\end{array}$ & $\begin{array}{c}3 \\
\text { (PBSt, LGS, MG) }\end{array}$ & & $\begin{array}{c}4 \\
\text { (TA, EDL, LGS, } \\
\text { MG) }\end{array}$ \\
\hline
\end{tabular}

Nine cats with a chronic hemisection and two with acute hemisection were studied. The reconstruction from histology showing the extent of damage in spinal cord tissue was obtained for eight of nine cats. For each cat, the number of active nerves (with rhythmic bursts of activity) in each hindlimb is indicated (rows 4 and 5) before and after complete spinalization ("spinal," rows 6 and 7). The status of three cats did not allow the study of spinal fictive locomotion.

and exteroceptive stimulation, there was still an asymmetry between the left and right sides in the ability to activate the locomotor networks. The postmortem histology in eight cats with chronic lesion showed that there was a clear asymmetry in the residual tracts between the left and right sides (Table 1). In five cats, most of the tissue of the left half of the cord was destroyed. In three cats, there was additional loss on the right side; in one cat, $3 / 4$ of the cord was lost but the right ventral quadrant was intact (Eidelberg et al., 1981; Little et al., 1988; Schucht et al., 2002; Martinez et al., 2011). This last cat showed similar results as the others and was thus included in the group.

\section{Gain of cutaneous pathways on the left and right side}

Apart from locomotor networks, many other spinal pathways can be modified by a partial spinal cord injury including reflex pathways (for review, see Frigon and Rossignol, 2006). Here, we compared the reflex gain (Lloyd, 1957; Capaday and Stein, 1986; Bennett et al., 1996; Brooke et al., 1997) of a cutaneous pathway on each side of the cord during fictive locomotion in cats with a chronic hemisection at $\mathrm{T} 10$, from the superficial peroneal nerve (innervating the dorsal surface of the hindpaw, SP) to the motor pool of the ankle flexor (TA). Such analysis was possible only with long episodes of fictive locomotion with a similar range of ENG bursts amplitude on both sides, which was rare considering the described asymmetry.

Figure $4 A$ illustrates the raw ENG bursts of TA muscle on the left (black) and on the right (gray) while the SP nerve was stimulated at the same intensity $(2.0 \mathrm{~T})$ on the left and on the right alternatively. Figure $4 B$ shows the averaged short-latency TA excitatory response to the cutaneous stimuli on each side. Figure $4, C-F$, illustrates the plots relating the amplitude of the reflex responses and the preceding ENG level of the locomotor burst for the left (filled dots) and the right (empty dots) sides. In Figure $4 C$ (same cat as for Fig. $4 A, B$ ), there was a linear regression on the left and on the right and the slope on the left side $\left(R^{2}=0.492\right)$ was significantly steeper than on the right $\left(R^{2}=0.152\right)$. This means that, for a similar locomotor burst, the reflex response was larger on the left, lesioned side than on the right side. Figure 4, $D$ and $E$, illustrates the results from two other cats with a chronic hemisection. In Figure $4 D$, the left side shows a linear relationship $\left(R^{2}=0.447\right)$, but not the right side. In Figure $4 E$, the slope on the left side $\left(R^{2}=0.569\right)$ appears steeper than on the right $\left(R^{2}=0.204\right)$, but the difference does not reach statistical significance $(p=0.09)$. Figure $4 F$ illustrates the data in a control cat with an acute hemisection. There were linear regressions on both the left $\left(R^{2}=0.681\right)$ and right $\left(R^{2}=0.615\right)$ sides, with no significant difference between them. In conclusion, compared with an acute hemisection, the chronic hemisection induced a significant asymmetry in the gain of cutaneous reflexes from SP to TA motor pools in two of three cats with a larger gain on the left side compared with the right.

\section{Discussion}

\section{Plasticity after the hemisection}

A convenient and well known conceptual framework to picture the neural control of locomotion is the tripartite system with facultative interactions among descending supraspinal commands, CPGs, and sensory feedback (Rossignol, 1996; Zehr and Duysens, 2004; Stuart, 2007). Under different conditions (developmental, learning, lesions, etc.), the weight of each part may be adjusted to produce an optimal walking performance. Our previous studies with a lateral hemisection have shown an adaptation in the interaction among the residual tracts from supraspinal structures, the CPG, and sensory feedback. After a complete section (T13) removing all voluntary commands, the walking patterns resulted from an adaptation of the CPG driven by sensory feedback. However, sensory feedback has the remarkable power to entrain CPGs in many species (Pearson et al., 1992; Andersson and Grillner, 1983; Elson et al., 1992; Kriellaars et al., 1994; McClellan and Jang, 1993; Conway et al., 1987; Lewis et al., 1990) and is also essential for the CPG to adapt after a complete section (Barbeau and Rossignol, 1987; De Leon et al., 1998). Moreover, treadmill training induces plasticity in reflex pathways (Côté et al., 2003; Côté and Gossard, 2004). The contribution of sensory feedback is thus very difficult to discard in the evaluation of plasticity. The results of this study on fictive locomotion, without phasic sensory feedback, provide for the first time direct electrophysiological evidence that there was a functional plasticity in locomotor CPGs after a partial SCI.

In all 9 cats with a left hemisection at T10 for 3 weeks, there were more hindlimb nerves with bursts of activity on the left side 
A

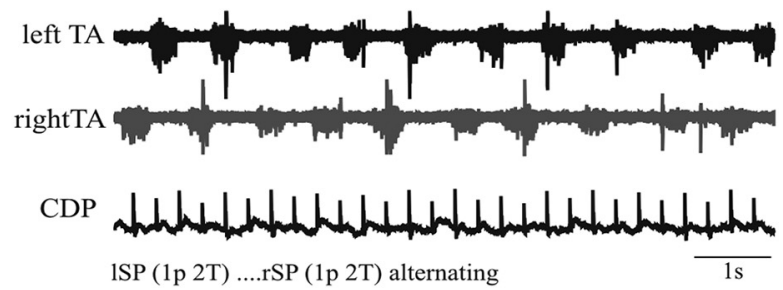

B

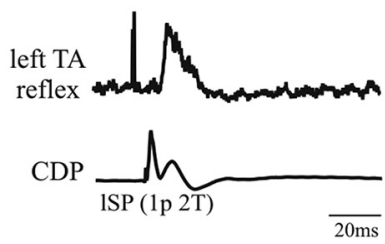

\section{Chronic left hemisection}

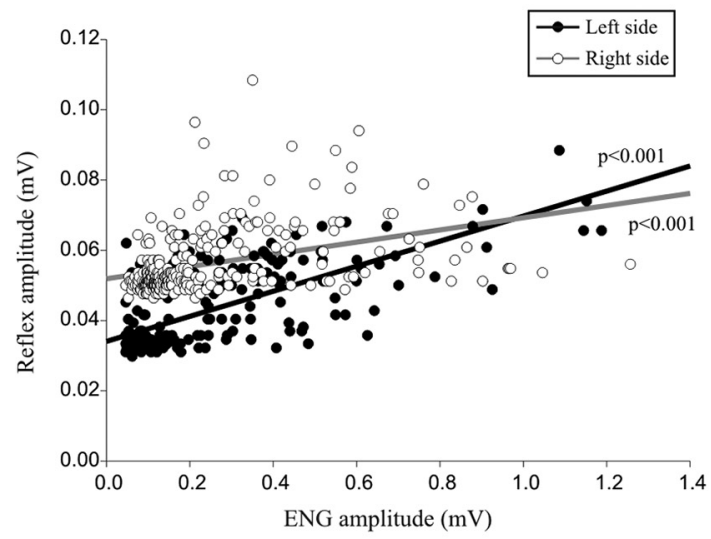

E Chronic left hemisection

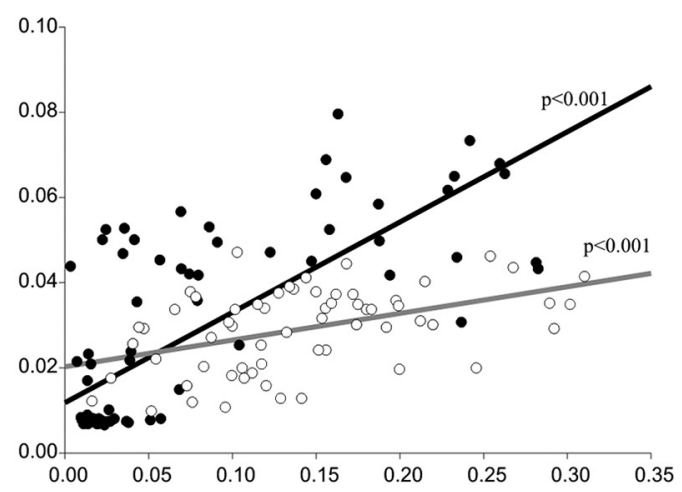

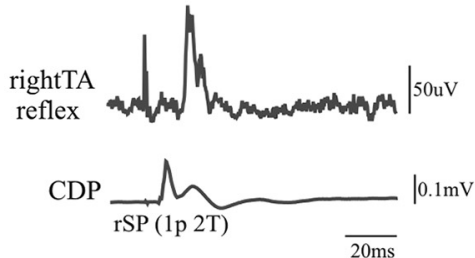

D Chronic left hemisection

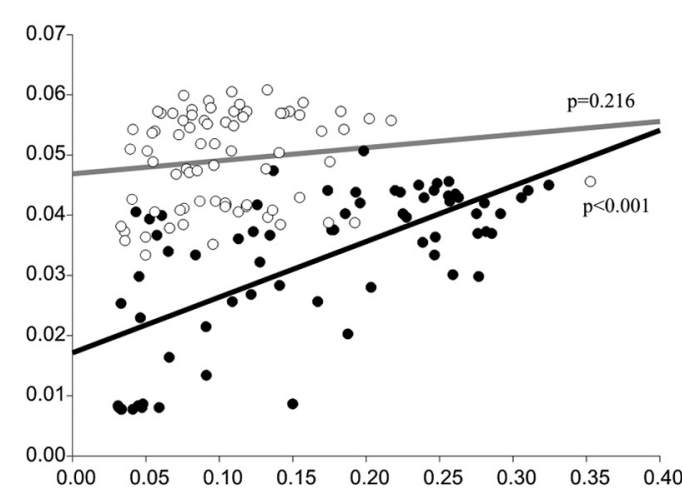

F Acute left hemisection

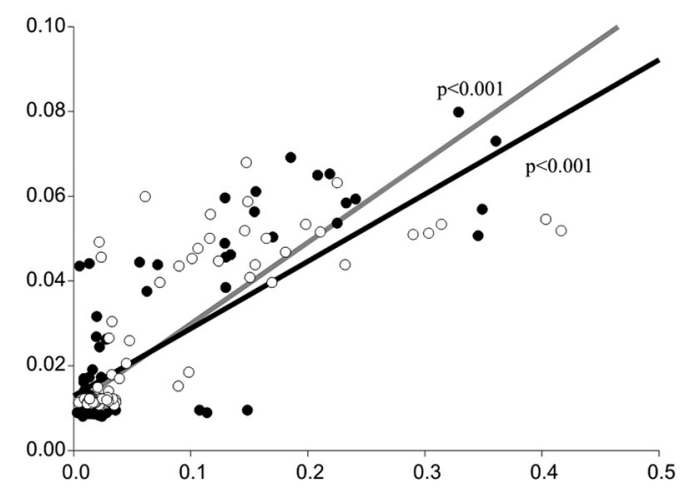

Figure 4. Left-right comparison of cutaneous transmission. $A$, Rhythmic alternating activity in left and right TA nerves and the CDP showing the incoming cutaneous volley from the repetitive stimulation of the left and right SP nerves. $\boldsymbol{B}$, Overall average of reflex response in TA nerves and CDP volleys. $\boldsymbol{C}-\boldsymbol{F}$, Plots relating reflex amplitude and ENG locomotor burst amplitude for the left TA (black dots) and right TA (empty dots) nerves from cats with a chronic hemisection $(\boldsymbol{C}-\boldsymbol{E})$ and from a cat with an acute hemisection $(\boldsymbol{F})$.

than on the right (36 vs 15) after decerebration (Table 1). The relationships between phases versus cycle duration indicated that the step cycle on the left side was more often extensor dominated (four of six cats), as in intact cats (Halbertsma, 1983; Gossard et al., 2011), than on the right side (two of six cats). The weakness in locomotor generation on the right side was not due to an overall depression in the excitability of motor pools because peripheral sensory stimuli could elicit large bursts of activity (Fig. 3B). In contrast, decerebration in otherwise intact cats led to a left-right symmetry in patterns of fictive locomotion (Fig. 1A). In addition, an acute hemisection in a control cat, disconnecting supraspinal structures on the left side, led to a net depression of locomotor activity on that side (Fig. 1B).

The prevalence of locomotor activity on the left-lesioned side may come as a surprise considering that the excitatory drive from the brainstem after decerebration was mostly reaching the right side. Two mechanisms may account for this. First, descending inputs were transmitted via crossed pathways to reach the left side. Functional recovery with an increased connectivity via crossed pathways after SCI have been reported before, including 
the brainstem (Matsuyama et al., 2004; Maier and Schwab, 2006; van den Brand et al., 2012; Filli et al., 2014; Zörner et al., 2014). Second, the disconnection from the ipsilateral descending pathways for 3 weeks may have induced an intrinsic spinal plasticity resulting in more autonomous activation of the CPG, a situation comparable to the adaptation after a chronic complete spinal cord section (De Leon et al., 1998; Lavrov et al., 2006; Rossignol and Frigon, 2011). The excitatory drive from crossed pathways, together with the spontaneous CPG autonomy, probably resulted in an enhanced excitability on the left side.

The right side responded much less in cats with a chronic left hemisection than in cats with an intact spinal cord. In other words, the right side was far from being an intact side, with a severely depressed CPG activity. The reason that the locomotor networks on the right side did not respond as well after decerebration is unknown. We can speculate that there was plasticity in supraspinal commands to the spinal cord networks on the right side during the 3 week period, possibly from reticular formation (Eidelberg et al., 1981; Eidelberg et al., 1986) and/or cortex that were lost or biased after the decerebration. Adaptation of supraspinal drive on the right side may also modify segmental networks projecting to hindlimb motoneurons (Bareyre et al., 2004; Ballermann and Fouad, 2006; Knikou and Mummidisetty, 2014).

There is ample evidence indicating plastic changes in the transmission in reflex pathways after SCI (Stein et al., 1991; Nielsen et al., 1995; Barbeau et al., 2002; Lee et al., 2005; Knikou et al., 2009; Singh et al., 2011; Frigon et al., 2012). In this study, we successfully compared the transmission in one cutaneous reflex pathway (from SP to TA) on each side of the cord in four cats with a chronic hemisection. The amplitude of cutaneous responses for a similar activation of the motor pool (ENG burst amplitude) was larger on the left than on the right side (significant in two of three cats). Because a change in reflex input-output gain is not simply related to background motoneuronal activity, it indicates that the change occurred at a premotoneuronal level, probably in cutaneous interneurons (Kernell and Hultborn, 1990; Hultborn et al., 2004). Such asymmetry was not seen in a control cat with an acute hemisection. The relative increase in reflex gain on the left is taken as further evidence for a left-right asymmetry in the plasticity after the hemisection. Because one side is relative to the other, another valid interpretation is that the gain of the reflex pathways was decreased on the right side compared with the left. Although we cannot favor one or the other based on our data, previous work comparing reflexes before and after lesion in the same animals reported an increased excitability on the side of the lesion. For example, in cats with a lateral hemisection, the stretch reflexes showed a decreased threshold and increased amplitude in the lesion side over time, whereas the same reflexes were similar to preinjury levels in the "intact side" (Murray and Goldberger, 1974). In addition, cutaneous afferents from the sural nerve activated more dorsal horn neurons on the side of the lesion in chronic hemisected cats (Brenowitz and Pubols, 1981). Previous studies assessing reflex pathways before and after a lateral hemisection have also observed such asymmetry (Hultborn and Malmsten, 1983a; Hultborn and Malmsten, 1983b). Overall, our limited sample suggests that the transmission in some cutaneous pathways showed plastic changes because of the incomplete SCI. Previous studies have reported that the locomotor system and reflexes have a parallel time course in their recovery after SCI and some investigators have proposed a causal relationship between the two processes (Murray and Goldberger, 1974; Pearson, 2001; Lavrov et al., 2006; Frigon and Rossignol, 2008; Dietz et al., 2009; Frigon et al., 2011).

\section{Plasticity revealed by the acute complete section}

If the hemisection induced profound changes in spinal cord intrinsic circuitry, then it should remain present even when all supraspinal pathways are removed (Hultborn and Malmsten, 1983a; Hultborn and Malmsten, 1983b; Barrière et al., 2008; Martinez et al., 2011). In this study, we successfully induced fictive locomotion in seven of nine cats with a chronic hemisection after an acute complete section of the cord at T13. The number of nerves with phasic bursts of activity was larger on the left, lesioned side compared with the right side ( 33 vs 25 ; Table 1 ). In addition, the relationship between phases and cycle duration showed that the cycle was extensor dominated on the left side (five of six cats), as in intact cats, more often than on the right side (two of six cats). Therefore, the removal of all supraspinal tracts did not erase all of the asymmetry seen before spinalization. That the left side responded better to spinalization and clonidine may again be explained by an enhanced autonomous activation of CPG brought about by the previous disconnection from the brain (Kato, 1989; De Leon et al., 1999; Rossignol and Frigon, 2011; Rossignol et al., 2011).

\section{CPG adaptation}

Cats used in this study remained in their cages after the SCI and were not trained to walk overground or on a treadmill, so there were limited locomotor-related descending commands and sensory feedback entering the spinal cord. The observed plasticity was thus mostly spontaneous. As reported previously (Barrière et al., 2008; Martinez et al., 2011), cats could walk on a treadmill with both hindlimbs 3 weeks after a left hemisection at T10 without training and the best stepping pattern was from the right hindlimb. In this situation, the tripartite system adapted quite successfully for the loss of supraspinal commands on one side to produce an efficient walking pattern. The CPG activity on the right side was controlled by residual supraspinal inputs and driven by rhythmic sensory feedback from the moving limbs. In our study, the CPG on the right side was deprived of many descending tracts (decerebration) and of all sensory activation and displayed poor autonomy. Overall, previous findings indicate that systems driving the CPGs are powerful and plastic and should be the target of rehabilitation strategies aimed at improving stepping recovery after an SCI. Findings from this study support the idea that CPG circuitry, and not only the systems impinging on it, is also amenable to plastic modifications.

\section{References}

Abraham LD, Marks WB, Loeb GE (1985) The distal hindlimb musculature of the cat. Cutaneous reflexes during locomotion. Exp Brain Res 58:594603. CrossRef Medline

Andersson O, Grillner S (1983) Peripheral control of the cat's step cycle II. Entrainment of the central pattern generators for locomotion by sinusoidal hip movements during "fictive locomotion." Acta Physiol Scand 118: 229-239. CrossRef Medline

Babu RS, Namasivayam A (2008) Recovery of bipedal locomotion in bonnet macaques after spinal cord injury: footprint analysis. Synapse 62:432447. CrossRef Medline

Ballermann M, Fouad K (2006) Spontaneous locomotor recovery in spinal cord injured rats is accompanied by anatomical plasticity of reticulospinal fibers. Eur J Neurosci 23:1988-1996. CrossRef Medline

Barbeau H, Rossignol S (1987) Recovery of locomotion after chronic spinalization in the adult cat. Brain Res 412:84-95. CrossRef Medline

Barbeau H, Ladouceur M, Mirbagheri MM, Kearney RE (2002) The effect of locomotor training combined with functional electrical stimulation in chronic spinal cord injured subjects: walking and reflex studies. Brain Res Rev 40:274-291. CrossRef Medline

Bareyre FM, Kerschensteiner M, Raineteau O, Mettenleiter TC, Weinmann O, Schwab ME (2004) The injured spinal cord spontaneously forms a 
new intraspinal circuit in adult rats. Nat Neurosci 7:269-277. CrossRef Medline

Barrière G, Leblond H, Provencher J, Rossignol S (2008) Prominent role of the spinal central pattern generator in the recovery of locomotion after partial spinal cord injuries. J Neurosci 28:3976-3987. CrossRef Medline

Bennett DJ, De Serres SJ, Stein RB (1996) Gain of the triceps surae stretch reflex in decerebrate and spinal cats during postural and locomotor activities. J Physiol 496:837-850. CrossRef Medline

Brenowitz GL, Pubols LM (1981) Increased response to sural nerve input in the dorsal horn following chronic spinal cord hemisection. Brain Res 208:421-425. CrossRef Medline

Brooke JD, Cheng J, Collins DF, McIlroy WE, Misiaszek JE, Staines WR (1997) Sensory-sensory afferent conditioning with leg movement: gain control in spinal reflex and ascending paths. Prog Neurobiol 51:393-421. CrossRef Medline

Capaday C, Stein RB (1986) Amplitude modulation of the soleus H-reflex in the human during walking and standing. J Neurosci 6:1308-1313. Medline

Conway BA, Hultborn H, Kiehn O (1987) Proprioceptive input resets central locomotor rhythm in the spinal cat. Exp Brain Res 68:643-656. Medline

Côté MP, Gossard JP (2004) Step training-dependent plasticity in spinal cutaneous pathways. J Neurosci 24:11317-11327. CrossRef Medline

Côté MP, Ménard A, Gossard JP (2003) Spinal cats on the treadmill: changes in load pathways. J Neurosci 23:2789-2796. Medline

De Leon R, Hodgson JA, Roy RR, Edgerton VR (1999) Retention of hindlimb stepping ability in adult spinal cats after the cessation of step training. J Neurophysiol 81:85-94. Medline

De Leon RD, Hodgson JA, Roy RR, Edgerton VR (1998) Locomotor capicity attributable to step training versus spontaneous recovery after spinalization in adult cats. J Neurophysiol 79:1329-1340. Medline

Dietz V, Grillner S, Trepp A, Hubli M, Bolliger M (2009) Changes in spinal reflex and locomotor activity after a complete spinal cord injury: a common mechanism? Brain 132:2196-2205. CrossRef Medline

Doperalski AE, Tester NJ, Jefferson SC, Howland DR (2011) Altered obstacle negotiation after low thoracic hemisection in the cat. J Neurotrauma 28:1983-1993. CrossRef Medline

Duysens J, Loeb GE (1980) Modulation of ipsi- and contralateral reflex responses in unrestrained walking cats. J Neurophysiol 44:1024-1037. Medline

Duysens J, Pearson KG (1976) The role of cutaneous afferents from the distal hindlimb in the regulation of the step cycle of thalamic cats. Exp Brain Res 24:245-255. Medline

Eidelberg E, Story JL, Walden JG, Meyer BL (1981) Anatomical correlates of return of locomotor function after partial spinal cord lesions in cats. Exp Brain Res 42:81-88. Medline

Eidelberg E, Nguyen LH, Deza LD (1986) Recovery of locomotor function after hemisection of the spinal cord in cats. Brain Res Bull 16:507-515. CrossRef Medline

Elson RC, Sillar KT, Bush BM (1992) Identified proprioceptive afferents and motor rhythm entrainement in the crayfish walking system. J Neurophysiol 67:530-546. Medline

Filli L, Engmann AK, Zörner B, Weinmann O, Moraitis T, Gullo M, Kasper H, Schneider R, Schwab ME (2014) Bridging the gap: a reticulopropriospinal detour bypassing an incomplete spinal cord injury. J Neurosci 34:13399-13410. CrossRef Medline

Fleshman JW, Lev-Tov A, Burke RE (1984) Peripheral and central control of flexor digitorium longus and flexor hallucis longus motoneurons: the synaptic basis of functional diversity. Exp Brain Res 54:133-149. Medline

Frigon A, Gossard JP (2009) Asymmetric control of cycle period by the spinal locomotor rhythm generator in the adult cat. J Physiol 587:46174628. CrossRef Medline

Frigon A, Gossard JP (2010) Evidence for specialized rhythm-generating mechanisms in the adult mammalian spinal cord. J Neurosci 30:70617071. CrossRef Medline

Frigon A, Rossignol S (2006) Functional plasticity following spinal cord lesions. Prog Brain Res 157:231-260. Medline

Frigon A, Rossignol S (2008) Adaptive changes of the locomotor pattern and cutaneous reflexes during locomotion studied in the same cats before and after spinalization. J Physiol 586:2927-2945. CrossRef Medline

Frigon A, Johnson MD, Heckman CJ (2011) Altered activation patterns by triceps surae stretch reflex pathways in acute and chronic spinal cord injury. J Neurophysiol 106:1669-1678. CrossRef Medline

Frigon A, Johnson MD, Heckman CJ (2012) Differential modulation of crossed and uncrossed reflex pathways by clonidine in adult cats following complete spinal cord injury. J Physiol 590:973-989. CrossRef Medline

Gossard JP, Sirois J, Noué P, Côté MP, Ménard A, Leblond H, Frigon A (2011) The spinal generation of phases and cycle duration. Prog Brain Res 188:15-29. Medline

Halbertsma JM (1983) The stride cycle of the cat: the modelling of locomotion by computerized analysis of automatic recordings. Acta Physiol Scand Suppl 521:1-75. Medline

Helgren ME, Goldberger ME (1993) The recovery of postural reflexes and locomotion following low thoracic hemisection in adult cats involves compensation by undamaged primary afferent pathways. Exp Neurol 123:17-34. CrossRef Medline

Hultborn H, Malmsten J (1983a) Changes in segmental reflexes following chronic spinal cord hemisection in the cat. I. Increased monosynaptic and polysynaptic ventral root discharges. Acta Physiol Scand 119:405-422. CrossRef Medline

Hultborn H, Malmsten J (1983b) Changes in segmental reflexes following chronic spinal cord hemisection in the cat. II. Conditioned monosynaptic test reflexes. Acta Physiol Scand 119:423-433. CrossRef Medline

Hultborn H, Brownstone RB, Toth TI, Gossard JP (2004) Key mechanisms for setting the input-output gain across the motoneuron pool. Prog Brain Res 143:77-95. Medline

Ichiyama RM, Courtine G, Gerasimenko YP, Yang GJ, van den Brand R, Lavrov IA, Zhong H, Roy RR, Edgerton VR (2008) Step training reinforces specific spinal locomotor circuitry in adult spinal rats. J Neurosci 28:7370-7375. CrossRef Medline

Kato M (1989) Chronically isolated lumbar half spinal cord, produced by hemisection and longitudinal myelotomy, generates locomotor activities of the ipsilateral hindlimb of the cat. Neurosci Lett 98:149-153. CrossRef Medline

Kernell D, Hultborn H (1990) Synaptic effects on recruitment gain: a mechanism of importance for the input-output relations of motoneurone pools? Brain Res 507:176-179. CrossRef Medline

Knikou M, Mummidisetty CK (2014) Locomotor training improves premotoneuronal control after chronic spinal cord injury. J Neurophysiol 111:2264-2275. CrossRef Medline

Knikou M, Angeli CA, Ferreira CK, Harkema SJ (2009) Soleus H-reflex modulation during body weight support treadmill walking in spinal cord intact and injured subjects. Exp Brain Res 193:397-407. CrossRef Medline

Kriellaars DJ, Brownstone RM, Noga BR, Jordan LM (1994) Mechanical entrainment of fictive locomotion in the decerebrate cat. J Neurophysiol 71:2074-2086. Medline

Kunkel-Bagden E, Dai HN, Bregman BS (1992) Recovery of function after spinal cord hemisection in newborn and adult rats: differential effects on reflex and locomotor function. Exp Neurol 116:40-51. CrossRef Medline

Lavrov I, Gerasimenko YP, Ichiyama RM, Courtine G, Zhong H, Roy RR, Edgerton VR (2006) Plasticity of spinal cord reflexes after a complete transection in adult rats: relationship to stepping ability. J Neurophysiol 96:1699-1710. CrossRef Medline

Lee JK, Emch GS, Johnson CS, Wrathall JR (2005) Effect of spinal cord injury severity on alterations of the H-reflex. Exp Neurol 196:430-440. CrossRef Medline

Lewis J, Bachoo M, Polosa C, Glass L (1990) The effects of superior laryngeal nerve stimulation on the respiratory rhythm: phase-resetting and aftereffects. Brain Res 517:44-50. Medline

Little JW, Harris RM, Sohlberg RC (1988) Locomotor recovery following subtotal spinal cord lesions in a rat model. Neurosci Lett 87:189-194. CrossRef Medline

Lloyd DPC (1957) Input-output relation in a flexor reflex. J Gen Physiol 41:297-306. CrossRef Medline

Maier IC, Schwab ME (2006) Sprouting, regeneration and circuit formation in the injured spinal cord: factors and activity. Philos Trans R Soc Lond B Biol Sci 361:1611-1634. CrossRef Medline

Martinez M, Delivet-Mongrain H, Leblond H, Rossignol S (2011) Recovery of hindlimb locomotion after incomplete spinal cord injury in the cat involves spontaneous compensatory changes within the spinal locomotor circuitry. J Neurophysiol 106:1969-1984. CrossRef Medline

Martinez M, Delivet-Mongrain H, Leblond H, Rossignol S (2012) Incom- 
plete spinal cord injury promotes durable functional changes within the spinal locomotor circuitry. J Neurophysiol 108:124-134. CrossRef Medline

Matsuyama K, Nakajima K, Mori F, Aoki M, Mori S (2004) Lumbar commissural interneurons with reticulospinal inputs in the cat: Morphology and discharge patterns during fictive locomotion. J Comp Neurol 474: 546-561. CrossRef Medline

McClellan AD, Jang W (1993) Mechanosensory inputs to the central pattern generators for locomotion in the lamprey spinal cord: resetting, entrainment, and computer modeling. J Neurophysiol 70:2442-2454. Medline

Michele Basso D, Murray M, Goldberger ME (1994) Differential recovery of bipedal and overground locomotion following complete spinal cord hemisection in cats. Restor Neurol Neurosci 7:95-110. Medline

Muir GD, Katz SL, Gosline JM, Steeves JD (1998) Asymmetric bipedal locomotion: an adaptive response to incomplete spinal injury in the chick. Exp Brain Res 122:275-282. CrossRef Medline

Murray M, Goldberger ME (1974) Restitution of function and collateral sprouting in the cat spinal cord: the partially hemisected animal. J Comp Neurol 158:19-36. CrossRef Medline

Nielsen J, Petersen N, Crone C (1995) Changes in transmission across synapses of Ia afferents in spastic patients. Brain 118:995-1004. CrossRef Medline

Pearson KG (2001) Could enhanced reflex function contribute to improving locomotion after spinal cord repair? J Physiol 533:75-81. CrossRef Medline

Pearson KG, Ramirez JM, Jiang W (1992) Entrainment of the locomotor rhythm by group Ib afferents from ankle extensor muscles in spinal cats. Exp Brain Res 90:557-566. Medline

Raineteau O, Schwab ME (2001) Plasticity of motor systems after incomplete spinal cord injury. Nat Rev Neurosci 2:263-273. CrossRef Medline

Rossignol S (1996) Neural control of stereotypic limb movements. In: Handbook of Physiology, section 12. Exercise: Regulation and integration of multiple systems (Rowell LB, Sheperd JT, eds), pp 173-216. Oxford: American Physiological Society.

Rossignol S, Frigon A (2011) Recovery of locomotion after spinal cord injury: some facts and mechanisms. Annu Rev Neurosci 34:413-440. CrossRef Medline

Rossignol S, Frigon A, Barrière G, Martinez M, Barthélemy D, Bouyer LJG, Bélanger M, Provencher J, Chau C, Brustein E, Barbeau H, Giroux N, Marcoux J, Langlet C, Alluin O (2011) Spinal plasticity in the recovery of locomotion. In: Progress in brain research: breathe, walk and chew, the neural challenge: part II (Gossard JP, Kolta A, Dubuc R, eds), pp 229-241. Amsterdam: Elsevier.
Roy RR, Harkema SJ, Edgerton VR (2012) Basic concepts of activity-based interventions for improved recovery of motor function after spinal cord injury. Arch Phys Med Rehabil 93:1487-1497. CrossRef Medline

Schucht P, Raineteau O, Schwab ME, Fouad K (2002) Anatomical correlates of locomotor recovery following dorsal and ventral lesions of the rat spinal cord. Exp Neurol 176:143-153. CrossRef Medline

Simonsen EB, Dyhre-Poulsen P (1999) Amplitude of the human soleus H reflex during walking and running. J Physiol 515:929-939. CrossRef Medline

Singh A, Balasubramanian S, Murray M, Lemay M, Houle J (2011) Role of spared pathways in locomotor recovery after body-weight-supported treadmill training in contused rats. J Neurotrauma 28:2405-2416. CrossRef Medline

Sirois J, Frigon A, Gossard JP (2013) Independent control of presynaptic inhibition by reticulospinal and sensory inputs at rest and during rhythmic activities in the cat. J Neurosci 33:8055-8067. CrossRef Medline

Smith PM, Jeffery ND (2005) Spinal shock: comparative aspects and clinical relevance. J Vet Intern Med 19:788-793. Medline

Stein RB, Yang JF, Edamura M, Capaday C (1991) Reflex modulation during normal and pathological human locomotion. In: Neurobiological basis of human locomotion (Shimamura M, Grillner S, Edgerton VR, eds), pp 335-346. Tokyo: Japan Scientific Society.

Stuart DG (2007) Reflections on integrative and comparative movement neuroscience. Integr Comp Biol 47:482-504. CrossRef Medline

van den Brand R, Heutschi J, Barraud Q, DiGiovanna J, Bartholdi K, Huerlimann M, Friedli L, Vollenweider I, Moraud EM, Duis S, Dominici N, Micera S, Musienko P, Courtine G (2012) Restoring voluntary control of locomotion after paralyzing spinal cord injury. Science 336:1182-1185. CrossRef Medline

Yakovenko S, McCrea DA, Stecina K, Prochazka A (2005) Control of locomotor cycle duration. J Neurophysiol 94:1057-1065. CrossRef Medline

Zehr EP, Duysens J (2004) Regulation of arm and leg movement during human locomotion. Neuroscientist 10:347-361. CrossRef Medline

Zhong G, Shevtsova NA, Rybak IA, Harris-Warrick RM (2012) Neuronal activity in the isolated mouse spinal cord during spontaneous deletions in fictive locomotion: insights into locomotor CPG organization. J Physiol 590:4735-4759. CrossRef Medline

Zörner B, Bachmann LC, Filli L, Kapitza S, Gullo M, Bolliger M, Starkey ML, Röthlisberger M, Gonzenbach RR, Schwab ME (2014) Chasing central nervous system plasticity: the brainstem's contribution to locomotor recovery in rats with spinal cord injury. Brain 137:1716-1732. CrossRef Medline 